\title{
The ejection and strength of binary iron-cellulose powder compacts
}

\begin{abstract}
In this study, the ejection stage during the densification process and the mechanical strength of green (unsintered) compact were studied for the binary powder compact of iron and micro crystalline cellulose (MCC). The mass percentage of MCC powder were varied between $0 \%$ to $60 \%$ of the total mass composition of the iron and MCC mixture. Three different compaction load of $30 \mathrm{kN}, 60 \mathrm{kN}$ and $90 \mathrm{kN}$ were applied during the compaction process. The tensile strength of the green compact was determined by conducting diametral compression test where the green compact was loaded until fracture. From the compaction experiment, green compact with $60 \%$ MCC and $40 \%$ iron is the least friable which leads to coherent and well compactable powder. This composition also results in the green compact with the highest tensile strength.
\end{abstract}

Keyword: Binary powder compaction; Diametral compression; Green strength; Iron powder; Micro crystalline cellulose (MCC) 